\title{
The crew timetabling problem: An extension of the crew scheduling problem
}

\author{
Marta Castilho Gomes • Luís Cavique · Isabel Themido
}

(C) Springer Science + Business Media, LLC 2006

\begin{abstract}
In some urban transportation companies driving periods are short when compared with the total duty time, leading to long non-driving periods that can be used as cover time. This paper presents the Crew Timetabling Problem, an extension of the Crew Scheduling Problem in which crew timetables are obtained by levelling the cover crew resources. An objective function for this problem is proposed in order to balance the number of driving and cover crews. A Lisbon Underground case study is used to illustrate The Crew Timetabling Problem. The problem is represented in a multigraph and solved by a tabu search-based heuristic.
\end{abstract}

Keywords Crew scheduling $\cdot$ Cover crews $\cdot$ Resource levelling $\cdot$ Multigraph $\cdot$ Tabu search

\section{Introduction}

Crew scheduling in transportation companies is a three-stage process. First, the timetables offered to the public are defined. Next, crew duties that cover those timetables are constructed. Finally, crew duties are assigned to workers on a rotating basis (crew rostering).

The crew duty construction stage involves two problems. The first one, known as the Crew Scheduling Problem (CSP), consists in covering a pre-defined vehicle timetable with the minimum number of (feasible) duties. CSP is a well known problem in the literature; important results are compiled in seven volumes of papers on Computer-Aided Scheduling of Public Transport edited since 1975 (Bodin and Berman, 1975; Daduna and Wren, 1988; Daduna, Branco, and Paixão, 1995; Desrochers and Rousseau, 1992; Rousseau, 1985; Wilson, 1999; Wren, 1981).

M. C. Gomes $(\bowtie) \cdot$ I. Themido $^{\dagger}$

CESUR, Instituto Superior Técnico, Lisboa, Av. Rovisco Pais, 1049-001 Lisboa, Portugal e-mail: marta.gomes@ist.utl.pt

L. Cavique

ESCS, Instituto Politécnico de Lisboa, Lisboa, Portugal; R. Carolina Michaelis Vasconcelos, 1500

Lisboa, Portugal

e-mail: 1cavique@escs.ipl.pt 
The solution of CSP defines the driving periods for each duty, but very often contractual rules at transportation companies force duties to be longer than the corresponding driving periods. This gives rise to periods where crews are on duty although not driving, which we denote non-driving periods in this paper. The problem of assigning duty start and finishing times, as well as break limits, resulting in a duty timetable or duty sheet, is the second problem faced while planning crew duties. This is the problem that we address in this paper and shall designate as the Crew Timetabling Problem (CTP).

In many public transportation companies driving periods form a large percentage of the total duty time and non-driving periods are short. In these cases, once CSP is solved, the duty sheet is obtained using some simple rules of thumb; for instance, non-driving periods are placed after driving periods so as to compensate for delays and avoid overtime payment.

However, in other transportation companies driving periods are short when compared with the total duty time, resulting in long non-driving periods where the crews may carry out additional tasks; one of these is to act as cover crews, ready to replace scheduled crews who fail to report for work. The time the crews spend driving, as cover crews or in the break(s) has to be tightly controlled at these companies. After CSP is solved, the problem of finding a duty timetable is thus a relevant one; the criterion followed is non-driving periods optimization. We did not find any reference to the Crew Timetabling Problem in the literature dedicated to crew scheduling, and so believe this to be the first description of the problem.

In this paper, after a definition of the terms used, we describe the performance measures developed for the Crew Timetabling Problem, which are combined in an objective function, and highlight the relation this problem bears to the Resource Levelling Problem. We present an algorithmic approach developed to solve CTP, which is based on tabu search, and describe it using a multigraph representation of the problem. We then present a case study application and discuss the results. We end with a summary and some concluding remarks.

\section{Definition of the terms used}

For full apprehension of this paper, we define the terms specific to Vehicle and Crew Scheduling used. Some of the terms are widely used in the literature-see for instance the glossary by Hartley (1981) — others had to be created to allow an accurate description of the Crew Timetabling Problem and the solution approach taken; these are marked with an asterisk.

- Block: the set of trips assigned to a vehicle for a day's work, including the time taken to leave and return to the depot.

- Timetable (vehicle timetable): a document showing all vehicle blocks in a day's work.

- Trip: a one-way movement of a vehicle between two terminuses. Trips are divided into increments of work for the purpose of crew scheduling.

- Increment of work: the portion of work between two adjacent relief times (corresponding to adjacent relief points). This is the smallest period, or elementary crew activity, into which the timetable can be divided.

- Relief point: a point along a line where a crew may leave a vehicle and another crew takes over; the vehicle continues in service. Relief points may be line terminuses or other intermediate points along a line.

- Piece of work: a set of consecutive increments of work from a single block. A piece of work is defined by the starting and finishing relief points and relief times as well as the vehicle identification. 
- Driving period* : a continuous time span where a crew is driving; it is composed of one or more pieces of work. In the last case the pieces of work are consecutive (not separated by breaks).

- Break: a rest period in a crew duty, often intended for the crew to have a meal.

- Non-driving period*: a continuous time span where a crew is on duty although not driving.

- Working period*: a continuous time span where a crew is on duty. It consists of driving and non-driving periods; in some cases a working period may consist only of a non-driving period (see Section 5-Case study). Different working periods in a duty are separated by breaks.

- CSP duty*: a crew duty with only its driving periods assigned. Solution of the Crew Scheduling Problem produces the set of CSP duties in a day's work.

- CTP duty*: a crew duty with its driving and working periods assigned. Assignment of working periods to a duty provides the times of duty start and finish as well as the start and end of its break or breaks.

- Duty sheet or duty timetable: a document showing all necessary details of each duty to the crew. A duty sheet is thus the set of CTP duties in a day's work i.e. the solution of the Crew Timetabling Problem.

- Cover crews: crews intended to replace scheduled crews who fail to report for work.

- Cover period*: a non-driving period where a crew acts as a cover crew.

- Wasted period* : a non-driving period too short to be a cover period.

To summarize, a CTP duty is composed of working periods and breaks. A working period consists of driving and non-driving periods. A non-driving period may be a cover period or a wasted period, depending on its length.

\section{Problem definition}

The Crew Timetabling Problem can be stated as follows: given a Crew Scheduling Problem solution, find a duty sheet (CTP solution) so as to obtain a well balanced cover crew profile. A cover crew profile is the number of cover crews available along the working day. The objective of CTP does not render itself to a simple definition as the one in CSP, whose aim is to minimize the number of crew duties used to cover a vehicle timetable.

Figure 1 depicts the driving crew profile for a real timetable (thick line) and the profile for the sum of the driving and cover crews if exact proportionality between the number of cover crews and the number of driving crews could be achieved at each moment (thin line). The latter is a target profile from which real cover crew profiles obtained when solving CTP will deviate; comparison between the real and the target cover crew profile is thus an important feature when assessing a cover crew profile generated by a duty sheet. Other relevant aspects in cover crew profile evaluation are the average number of cover crews (during the day or in certain periods such as the rush hours) and the extent of cover crew availability at relief points.

In this section, different performance measures to assess cover crew profiles are presented and rigorously defined, and an objective function for CTP based on these measures is proposed.

\subsection{Cover crew profile}

Let $C=\left\{c_{1}, c_{2}, \ldots, c_{K}\right\}$ be the set of cover periods in a duty timetable (a CTP solution). Some CTP duties may have one or more cover periods while others will have none. Each 


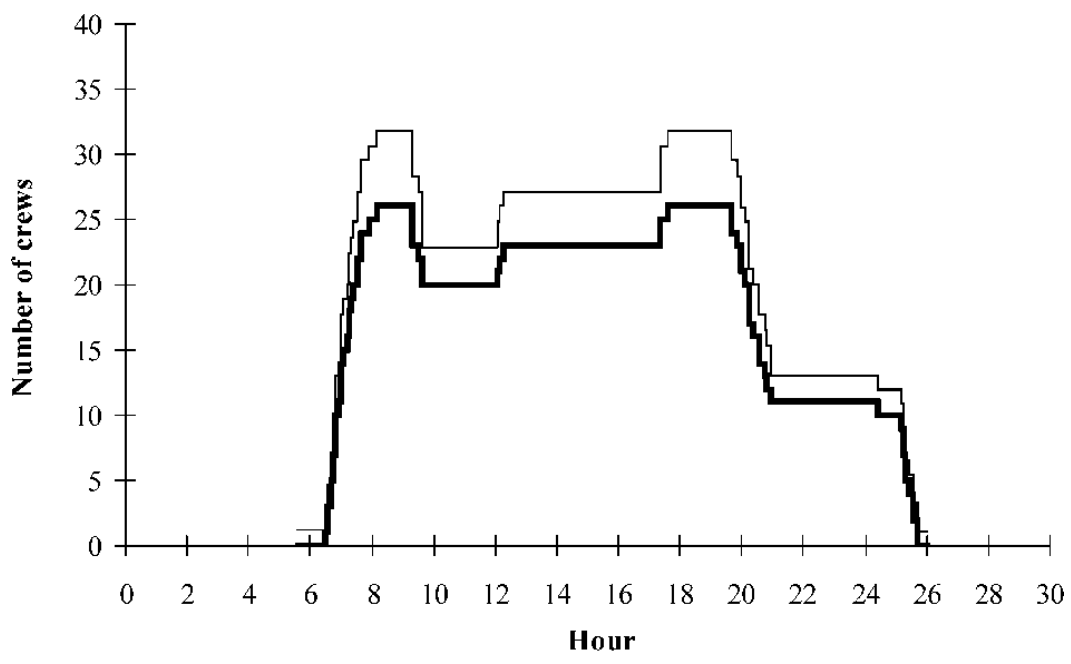

- Driving crews $\quad$ Driving + cover crews (Proportional profile)

Fig. 1 Driving and cover crew profiles

cover period $c_{j} \in C$ is considered independently of the CTP duty to which it belongs and has three attributes: its start and finishing times, $S_{j}$ and $F_{j}$, respectively, and the relief point $R_{j}$ where the crew stays during the cover period.

For each $c_{j} \in C$ we define function $f_{j}(t)$ as:

$$
\begin{array}{r}
f_{j}(t): \quad I R_{0}^{+} \rightarrow\{0,1\} \\
f_{j}(t)= \begin{cases}1 & \text { if } S_{j} \leq t \leq F_{j} \\
0 & \text { if } t\left\langle S_{j} \vee t\right\rangle F_{j}\end{cases}
\end{array}
$$

indicating whether cover period $c_{j}$ contains (or covers) time period $t$ or not.

The cover crew profile corresponding to set $C$ is the function obtained by adding the $f_{j}$ functions at time period $t$ :

$$
\begin{gathered}
C(t): I R_{0}^{+} \rightarrow I N_{0} \\
C(t)=\sum_{j=1}^{K} f_{j}(t)
\end{gathered}
$$

and equals the number of cover crews at $t$. $C(t)$ is a step function, constant between successive jump points. Figure 2 illustrates computation of the cover crew profile for a given set of cover periods.

Since it is during the time span of vehicle circulation that crew replacement may be needed, a performance measure for a duty timetable is the average number of cover crews in that interval. Assuming a continuous time span $\left[t_{S}, t_{F}\right]$ for vehicle circulation, we define $T_{1}$ as the set of start and finishing times of the cover periods in $C$ and $T_{2}$ as the set of start and $\underline{\text { Springer }}$ 




Fig. 2 Computation of the cover crew profile for a set of cover periods

finishing times contained in interval $] t_{S}, t_{F}\left[\right.$ together with moment $t_{S}$ :

$$
\begin{aligned}
& T_{1}=\left\{S_{j}, F_{j}: c_{j} \in C\right\} \\
& T_{2}=\left(T_{1} \cap\right] t_{S}, t_{F}[) \cup\left\{t_{S}\right\} .
\end{aligned}
$$

The average number of cover crews during vehicle circulation, obtained by integrating $C(t)$ in interval $\left[t_{S}, t_{F}\right]$, may then be expressed as:

$$
\bar{C}=\frac{\sum_{t_{i} \in T_{2}} C\left(t_{i}\right) \cdot\left(t_{i+1}-t_{i}\right)}{t_{F}-t_{S}}
$$

where $t_{i+1}$ designates the element following $t_{i}$ when set $T_{2}$ is considered in increasing time order; the element following the last element in $T_{2}$ is $t_{F}$. Computation of the average number of cover crews may be restricted to an interval $I \subset\left[t_{S}, t_{F}\right]$, for instance, a rush hour period; in that case the average number of cover crews is obtained by integrating $C(t)$ in interval $I$ and dividing by the interval length.

Instead of the global average number of cover crews, we may be interested in the average number of cover crews in a given relief point $Y$. Function $f_{j, Y}(t)$ must then be defined for each $c_{j} \in C$, indicating whether cover period $c_{j}$ provides a cover crew at relief point $Y$ and time period $t$ :

$$
\begin{array}{r}
f_{j, Y}(t): I R_{0}^{+} \rightarrow\{0,1\} \\
f_{j, Y}(t)= \begin{cases}1 & \text { if } S_{j} \leq t \leq F_{j} \wedge R_{j}=Y \\
0 & \text { if } t\left\langle S_{j} \vee t\right\rangle F_{j} \vee R_{j} \neq Y\end{cases}
\end{array}
$$


The cover crew profile at terminus $Y, C_{Y}(t)$, is obtained by adding the $f_{j, Y}$ functions at time period $t$; the average number of cover crews at terminus $Y$ in a given interval is obtained by integrating function $C_{Y}(t)$ in the interval and dividing by the corresponding interval length.

\subsection{Uniform profile}

Comparison between the real and the target cover crew profiles must be translated into a performance measure. Two target profiles may be suitable in the context of the Crew Timetabling Problem.

The first one is the Uniform Profile, which displays a constant number $K$ of cover crews throughout the day. The difference $C(t)-K$ is the deviation (positive or negative) between the real and the Uniform Profile; comparison is restricted to the time span of vehicle circulation $\left[t_{S}, t_{F}\right]$. If $K$ is equal to the average number of cover crews $\bar{C}$ in interval $\left[t_{S}, t_{F}\right]$, the sum of the deviations between $C(t)$ and $K$ is zero:

$$
\sum_{t_{i} \in T_{2}}\left(C\left(t_{i}\right)-\bar{C}\right) \cdot\left(t_{i+1}-t_{i}\right)=0 .
$$

We then define a deviation function in interval $\left[t_{S}, t_{F}\right]$ which is the absolute value of the difference $C(t)-\bar{C}$ :

$$
\begin{array}{r}
\Delta C_{U}(t):\left[t_{S}, t_{F}\right] \rightarrow I R_{0}^{+} \\
\Delta C_{U}(t)=|C(t)-\bar{C}|
\end{array}
$$

and will use the average value of $\Delta C_{U}(t)$ to quantify adherence of the real cover crew profile to the Uniform Profile:

$$
\overline{\Delta C}_{U}=\frac{\sum_{t_{i} \in T_{2}} \Delta C_{U}\left(t_{i}\right) \cdot\left(t_{i+1}-t_{i}\right)}{t_{F}-t_{S}} .
$$

\subsection{Proportional profile}

Since cover crews replace crews who fail to report for work, a higher number of cover crews is needed when the number of driving crews is also higher. A Proportional Profile, which displays a number of cover crews proportional to the number of driving crews, may thus be more attractive than the Uniform Profile in the Crew Timetabling Problem context. Computation of the average deviation from the Proportional Profile requires the definition of the driving crew profile for a duty sheet. This is similar to the definition of the cover crew profile except that driving periods instead of cover periods are considered.

Let $P=\left\{p_{1}, p_{2}, \ldots, p_{N}\right\}$ be the set of driving periods or pieces of work in a duty sheet. Each driving period $p_{m} \in P$ has a starting time $S_{m}$ and a finishing time $F_{m}$ and an associated function $g_{m}(t)$ defined as:

$$
\begin{array}{r}
g_{m}(t): I R_{0}^{+} \rightarrow\{0,1\} \\
g_{m}(t)= \begin{cases}1 & \text { if } S_{m} \leq t \leq F_{m} \\
0 & \text { if } t\left\langle S_{m} \vee t\right\rangle F_{m}\end{cases}
\end{array}
$$

indicating whether driving period $p_{m}$ contains (or covers) time period $t$ or not. 
The driving crew profile corresponding to $P$ is the function $D(t)$ obtained by adding the $g_{m}$ functions at time period $t$ :

$$
\begin{gathered}
D(t): I R_{0}^{+} \rightarrow I N_{0} \\
D(t)=\sum_{m=1}^{N} g_{m}(t) .
\end{gathered}
$$

In the Proportional Profile the number of cover crews is equal to a constant $K$ times $D(t)$; the deviation between the real and the Proportional Profile is then equal to $C(t)-K \cdot D(t)$. Let $T_{3}$ be the set of start and finishing times of the driving periods in $P$ and $T_{4}$ the set of start and finishing times of cover and driving periods in interval $\left[t_{S}, t_{F}[\right.$ :

$$
\begin{aligned}
& T_{3}=\left\{S_{j}, F_{j}: p_{j} \in P\right\} \\
& T_{4}=\left(T_{1} \cup T_{3}\right) \backslash\left\{t_{F}\right\} .
\end{aligned}
$$

The value:

$$
K=\frac{\sum_{t_{i} \in T_{4}} C\left(t_{i}\right) \cdot\left(t_{i+1}-t_{i}\right)}{\sum_{t_{i} \in T_{4}} D\left(t_{i}\right) \cdot\left(t_{i+1}-t_{i}\right)}=\frac{\bar{C}}{\bar{D}}
$$

(with $\bar{C}$ and $\bar{D}$ computed in interval $\left[t_{S}, t_{F}\right]$ ) assures the sum of the deviations to be zero:

$$
\sum_{t_{i} \in T_{4}}\left(C\left(t_{i}\right)-K \cdot D\left(t_{i}\right)\right) \cdot\left(t_{i+1}-t_{i}\right)=0
$$

We define the deviation function as the absolute value of the difference $C(t)-K \cdot D(t)$ :

$$
\begin{aligned}
& \Delta C_{P}(t):\left[t_{S}, t_{F}\right] \rightarrow I R_{0}^{+} \\
& \Delta C_{P}(t)=|C(t)-K \cdot D(t)| \quad K=\frac{\bar{C}}{\bar{D}}
\end{aligned}
$$

and will use the average value of $\Delta C_{P}(t)$ to quantify adherence of the real cover crew profile to the Proportional Profile:

$$
\overline{\Delta C}_{P}=\frac{\sum_{t_{i} \in T_{4}} \Delta C_{P}\left(t_{i}\right) \cdot\left(t_{i+1}-t_{i}\right)}{t_{F}-t_{S}} .
$$

\subsection{Uncovered intervals}

A further important aspect when evaluating Crew Timetabling Problem solutions (duty sheets) is cover crew availability at relief points during the time span of vehicle circulation. In fact, a desirable aim when solving CTP is always to have one (or more) cover crews available at line terminuses or other relief points, ready to report to duty. To compute the total time length where a relief point $Y$ is uncovered by the cover crews provided by a duty timetable, a new binary function $h_{Y}(t)$ needs to be defined. $h_{Y}(t)$ is equal to 1 if $Y$ is uncovered by cover 
crews at time period $t$ and 0 otherwise; it is computed by adding all $f_{j, Y}(t)$ values at time period $t$ :

$$
\begin{array}{r}
h_{Y}(t): I R_{0}^{+} \rightarrow\{0,1\} \\
h_{Y}(t)= \begin{cases}1 & \text { if } \sum_{j=1}^{n} f_{j, Y}(t)=0 \\
0 & \text { if } \sum_{j=1}^{n} f_{j, Y}(t)>0\end{cases}
\end{array}
$$

By using function $h_{Y}(t)$, the total time length $T(Y)$ where relief point $Y$ is uncovered by cover crews during the time span of train circulation is calculated as:

$$
T(Y)=\sum_{t_{i} \in T_{2}} h_{Y}\left(t_{i}\right) \cdot\left(t_{i+1}-t_{i}\right)
$$

\subsection{Objective function}

Combination of performance measures average number of cover crews and average deviation from the target profile in an objective function requires the values to be standardized to the same scale. Since higher values for the average number of cover crews are preferable, standardization to the $[0,1]$ scale is done as follows:

$$
\bar{C}_{S T}=\frac{\bar{C}-\bar{C}_{\min }}{\bar{C}_{\max }-\bar{C}_{\min }}
$$

where $\bar{C}_{\max }$ and $\bar{C}_{\min }$ are the maximum and minimum values of the average number of cover crews observed for different CTP solutions (duty sheets) generated for the same CSP solution. As to the average deviation from the target profile, lower values are preferable, since maximum adherence to the target profile is desirable. Hence, standardized values in the $[0,1]$ scale are calculated in the following way:

$$
\overline{\Delta C}_{\mathrm{sT}}=\frac{\overline{\Delta C}_{\max }-\overline{\Delta C}}{\overline{\Delta C}_{\max }-\overline{\Delta C}_{\min }}
$$

where $\overline{\Delta C}_{\max }$ and $\overline{\Delta C}_{\min }$ are the maximum and minimum values of the average deviation from the (generic) target profile obtained by generating different CTP solutions (duty sheets) for the same CSP solution.

In objective function $F$ (to be maximized) the average number of cover crews and the average deviation from the target profile are combined in a linear trade-off term with parameter $\alpha$ while unavailability of cover crews at relief points constitutes a penalty term with weight $\omega$ :

$$
F=\alpha \bar{C}_{S T}+(1-\alpha) \overline{\Delta C}_{S T}-\omega \sum_{Y_{i} \in \mathcal{R}} T\left(Y_{i}\right) \quad 0 \leq \alpha \leq 1
$$

( $\mathcal{R}$ is the set of relief points where cover crews are required). 


\subsection{The Crew Timetabling Problem and the Resource Levelling Problem}

An interesting parallel may be drawn between the Crew Timetabling Problem and the Resource Levelling Problem (RLP) in the Project Scheduling field. This problem arises when smoothing of the resource utilization profile during a project execution is required. Different measures of the variation of resource utilization, to be minimized, may be considered in RLP (Neumann and Zimmermann, 1999).

Levelling of the resource utilization profile in RLP is achieved by shifting the non-critical activities within their available floats (that is to say, between their earliest and latest times), so that the project duration remains fixed (Bandelloni et al., 1994). Likewise, levelling of the cover crew profile in CTP requires shifting the start and end of the working periods within the limits allowed by the problem constraints. A noteworthy difference between the two problems is that while RLP attempts to level resources consumed by activities, in CTP the resources to be levelled are the crews freed from the "driving activities".

Figure 3 illustrates working periods shifting for a crew duty with two working periods. Duty and break starts (which are the same as the start and end of the first working period) may be shifted independently within earliest and latest times. Duty start cannot take place later than its latest time due to the need to include a report time, the time allowed for a crew to sign-on and prepare for work at the start of a duty. On the other hand, a duty cannot start before its earliest time because of the need to include a clear time, the time the crew needs to complete sign-off procedures at duty end. A minimum time period before and after the break also has to be considered in duties, which leads to earliest and latest times for the break start.

Figure 3 displays three CTP duties corresponding to the same CSP duty obtained by differently assigning the start and end of the first working period. When the resulting nondriving periods are long enough, crews are on call; otherwise the non-driving periods are wasted and do not contribute to the cover crew profile. This is illustrated in Figure 3; two of the CTP duties display two cover periods each while the third one has no cover periods because the non-driving periods are too short.



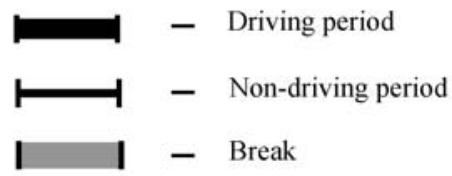

Fig. 3 Shifting of working periods

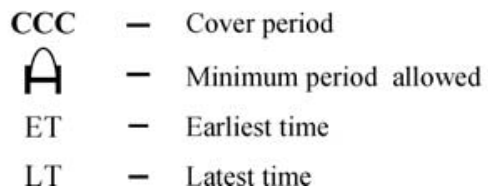

$\mathrm{CCC}-$ Cover period

ET - Earliest time

LT - Latest time 
When duty and break length are fixed, as assumed in Figure 3, no earliest and latest times for the start and end of the second working period need to be considered because they cannot be shifted independently from the first working period. However, when duty or break length are variable, earliest and latest times must also be considered for duty or break end.

\section{The algorithmic approach}

This section describes a heuristic procedure to construct initial solutions for the Crew Timetabling Problem and a local search heuristic based on tabu search to improve them. Since tabu search is now a well established metaheuristic method (Glover, 1995; Glover and Laguna, 1997), only the most relevant aspects of its implementation in the CTP context are highlighted here; Gomes, Cavique and Themido (2002) provide a thorough description of the algorithms used.

Description of the solution procedure uses a multigraph representation of the Crew Timetabling Problem with the underlying hypothesis that duties may include one or two driving periods. This is a feature displayed by duties in the case study described in this paper but is quite common in public transportation companies (Hartley, 1981).

\subsection{Multigraph representation of the crew timetabling problem}

To solve the Crew Scheduling Problem Cavique, Rego, and Themido (1999) use a graph representation of the problem where nodes depict driving periods and edges represent the possible matchings of driving periods to form two period duties. The Crew Timetabling Problem requires a multigraph representation $M G(P, D)$ where edges represent CTP duties and the multigraph or multiple edge structure derives from the existence of several CTP duties for the same CSP duty i.e. several ways of assigning the start and end of the working periods of the CTP duty corresponding to a given CSP duty. Representation of node set $P$ and duty set $D$ is as follows:

$$
\begin{aligned}
& P=\left\{p_{1}, p_{2}, \ldots, p_{N}\right\} \\
& D=\left\{\left(p_{i}, p_{j}, k\right): p_{i}, p_{j} \in P \wedge k \in K\left(p_{i}, p_{j}\right)\right\}
\end{aligned}
$$

where $N$ is the number of nodes (driving periods); $\left(p_{i}, p_{j}, k\right)$ is the $k$ th feasible CTP duty for the CSP duty containing driving periods $p_{i}$ and $p_{j} ; \lim \left(p_{i}, p_{j}\right)$ is the number of different feasible CTP duties for the CSP duty containing driving periods $p_{i}$ and $p_{j} ; K\left(p_{i}, p_{j}\right)=\{1$, $\left.2, \ldots, \lim \left(p_{i}, p_{j}\right)\right\}$ is the set of indices for the above CTP duties.

Nodes $p_{i}$ and $p_{j}$ may be the same driving period; in that case edge $\left(p_{i}, p_{i}, k\right)$ represents a CTP duty with a single driving period.

The multigraph representation is illustrated in Figure 4. Only two train blocks are considered because a higher number of blocks would make the representation too cumbersome. The blocks were previously divided into nine driving periods by the Crew Scheduling Problem. We assume that the set of rules that duties have to satisfy only allows driving periods $p_{1}, p_{4}$, $p_{6}, p_{8}$ and $p_{9}$ to be placed in single-driving-period duties; the loops around them represent the corresponding CTP duties. The remaining edges represent CTP duties corresponding to the feasible matchings of driving periods to form two-driving-period duties. Matchings are allowed for non-overlapping driving periods "close" in time (otherwise the duration of the duty would exceed the limit) but not so close that there is no room for the break. Only some 且 Springer 




Fig. 4 Multigraph representation of the Crew Timetabling Problem

of the edges are marked with the $\left(p_{i}, p_{j}, k\right)$ notation to avoid an excess of information in Figure 4.

A CTP solution is a collection of edges $\mathrm{S} \subset \mathrm{D}$ such that:

- every two edges are vertex disjoint;

- every $p_{i} \in P$ is incident with one edge in $\mathrm{S}$, which is either a $\operatorname{loop}\left(p_{i}\right.$ is unmatched) or an edge matching it to another driving period.

The edges marked with a thick line in Figure 4 define a CTP solution for the multigraph depicted.

The multigraph representation of the Crew Timetabling Problem may be generalized to the case where crew duties may contain any number of driving periods by allowing edges to join more than two vertices, thus representing CTP duties with more than two driving periods. In this generalization the graph is transformed into a hypergraph where edges may be associated with a single vertex (loops), a pair of vertices or arbitrary subsets of vertices (Wilson and Watkins, 1990). Again, multiple edges are needed to represent the set of CTP duties that may correspond to the same CSP duty (subset of vertices).

\subsection{Generating an initial solution for the problem}

Initial solutions for the problem are generated from a pre-defined CSP solution. First, all CTP duties corresponding to the CSP duties in the solution provided are systematically generated. This is done by calculating the earliest and latest times for the start and end of the working periods of each duty (see Figure 3) and then shifting the working period limits between them. Practical reasons impose this shifting process to be generally done in discrete intervals and not continuously. For instance, at Lisbon Underground (the company of the case study) working periods must start and finish at the hour or at a quarter past, at half past or at a quarter 
to. Hence, the working period limits are shifted between their earliest and latest times by 15 minute intervals.

Several constructive heuristics may then be applied to the set of CTP duties generated so as to obtain initial solutions for the problem. The best results in the case study were obtained with the maximization of cover time heuristic. This consists in selecting, for each CSP duty, the CTP duty with maximum total cover time (the total cover time of a CTP duty is the sum of its cover periods). As to CSP duties that do not have CTP duties with cover periods (because the non-driving periods are all too short), the CTP duty is arbitrarily chosen since it does not have an influence upon the solution.

\subsection{Improving problem solutions}

Initial solutions of CTP generated by the maximization of cover time heuristic are improved by shifting cover periods away from time intervals with an excess of cover crews and into time intervals that are short of these crews.

Different kinds of moves are used in the local search procedure. The first one, named shifting of working periods, corresponds to reassigning the start and end of a duty working periods without changing the driving periods, i.e. choosing a different CTP duty for the same CSP duty. This move corresponds in the multigraph to replacing edge $\left(p_{i}, p_{j}, k_{1}\right)$ by edge $\left(p_{i}, p_{j}, k_{2}\right)$ :

Shifting of working periods:

$$
\left(p_{i}, p_{j}, k_{1}\right) \rightarrow\left(p_{i}, p_{j}, k_{2}\right) \quad \begin{array}{lll}
p_{i}=p_{j} & \text { or } & p_{i} \neq p_{j} \\
k_{1}, k_{2} \in K\left(p_{i}, p_{j}\right) & \text { and } \quad k_{1} \neq k_{2}
\end{array}
$$

The second move, named switching of driving periods, swaps driving periods between pairs of duties; driving periods may be swapped in a pair of two-driving-period-duties or between a two-driving-period-duty and a single-driving-period-duty. While shifting moves do not change the CSP duties in a problem solution, switching moves produce new CSP duties i.e. the CSP solution underlying a CTP solution is changed. Driving periods may be swapped in two different ways, although in general only one leads to feasible CSP duties; this is illustrated below:

Swap in a pair of two-driving-period-duties:

$$
\begin{aligned}
& \left(p_{i}, p_{j}, k_{1}\right)+\left(p_{m}, p_{n}, k_{2}\right) \searrow_{\left(p_{i}, p_{n}, k_{5}\right)+\left(p_{j}, p_{m}, k_{6}\right) k_{5} \in K\left(p_{i}, p_{n}\right), k_{6} \in K\left(p_{j}, p_{m}\right)}{ }_{k_{1} \in K\left(p_{i}, p_{j}\right), k_{2} \in\left(p_{m}, p_{n}\right)}
\end{aligned}
$$

Swap between a two-driving-period-duty and a single-driving-period-duty:

$$
\begin{aligned}
& \left(p_{i}, p_{j}, k_{1}\right)+\left(p_{m}, p_{m}, k_{2}\right) \searrow_{\left(p_{j}, p_{m}, k_{5}\right)+\left(p_{i}, p_{i}, k_{6}\right)} k_{5} \in K\left(p_{j}, p_{m}\right), k_{6} \in K\left(p_{i}, p_{i}\right) \\
& k_{1} \in K\left(p_{i}, p_{j}\right), k_{2} \in K\left(p_{m}, p_{m}\right)
\end{aligned}
$$

Besides driving periods switching, simultaneous shifting of working periods in a pair of duties is also considered. 
Examining every solution in the neighbourhood of the current solution at each step would be too time consuming. Thus, a subset of the neighbourhood-a sub-neighbourhood-that contains a reduced number of high quality solutions is considered. Sub-neighbourhoods are generated by means of a Local Evaluation Function that quantifies the expected benefit of inserting a CTP duty (or pair of duties) from a candidate list into the current solution. Intersections of the CTP duty cover periods with the time intervals where the current solution has a number of cover crews below the daily average and with the time intervals where these crews exceed the daily average are calculated, and the Local Evaluation Function expressed as the difference between these values. A few duties (or duty pairs) with the higher values of the Local Evaluation Function are selected and the solutions in the sub-neighbourhood generated by the exchange moves described; the corresponding objective function values are calculated and the best solution chosen.

Tabu lists were implemented as sets of CTP duties, and two different strategies for managing them were devised. As a result of the first strategy, Tabu Out, a CTP duty (edge) or pair of CTP duties (depending on the neighbourhood type) dropped from a solution is prevented from re-entering problem solutions for a number of iterations $T$ (the tabu tenure). With the second strategy, Tabu In, the CTP duty or pair of CTP duties added to a solution is kept in the solutions visited in the following $T$ iterations. Experimentation lead to the conclusion that the most effective way of managing the tabu list is to alternate both strategies along the search instead of using a single one.

For further description of the algorithms used in the local search procedure refer to Gomes, Cavique and Themido (2002).

\section{Case study}

\subsection{Description}

Lisbon Underground network has been undergoing extensive alteration and expansion and the need to define and solve the Crew Timetabling Problem arose while developing a Decision Support System to assist vehicle and crew scheduling at this company.

Crew duties at Lisbon Underground (LU) consist of two working periods separated by a break, usually placed at lunch or dinner time; duty and break length are fixed. According to the number of driving periods, LU duties can be classified as: two-driving-period duties, which include one driving period in each working period; single-driving-period-duties, with only one driving period either in the first or in the second working period, and full-coverduties without driving periods. There are no relief points between line terminuses at LU, which means increments of work correspond to trips. Driving periods contain only one piece of work each and there are no extra-boards (short pieces of work not included in duties). Duties have to fulfill an extensive set of rules described in the Appendix.

The Crew Scheduling Problem was solved by Cavique, Rego, and Themido (1999) for LU timetables using a traditional run-cutting approach followed by the application of two alternative improvement algorithms embedded in a tabu search framework: Tabu-Crew takes advantage of a form of strategic oscillation for the neighbourhood search while the RunEjection algorithm considers compound moves based on a subgraph ejection chain method. The number of duties is minimized by covering train timetables with two-driving-period duties whenever possible and including the driving periods that cannot be matched in singledriving-period duties.

After CSP is solved, construction of a duty sheet is guided by the Lisbon Underground policy regarding cover crews. At LU, cover crews are required to be present at each line 
terminus during the work day. Since strict limits to driving time result in long non-driving periods in LU duties, crews with an assigned duty and long non-driving periods may be used as cover crews. CTP is therefore a relevant problem at LU because by constructing a duty sheet that optimizes non-driving periods, the need for full-cover-duties is minimized.

Optimization of cover crews at LU is especially important for weekday timetables where a higher number of cover crews are needed in the morning and afternoon rush hours in contrast with a lower number needed in the hours of lesser passenger influx. Hence, the timetable used in this paper to illustrate and solve CTP is a timetable for weekdays provided by Lisbon Underground. It corresponds to a stage in the network expansion process where there were two lines and two terminuses: line 1 connecting terminus $\mathrm{A}$ and $\mathrm{B}$ and line 2 starting and ending at terminus A (a circular line).

The number of driving crews during the day corresponding to this timetable is shown in Figure 1. Five periods, where the number of driving crews is constant, can be identified in this profile: morning rush hour, late morning, afternoon, evening rush hour and night. Transitions between these periods are steep (the number of crews varies quite rapidly). The number of trains in circulation reaches 26 at the rush hours.

Trips between terminuses last about 30 minutes in both lines of the network, which means it takes one hour to get back to terminus A or B in line 1 and half an hour to get back to terminus $\mathrm{A}$ in line 2 . As a consequence, if a non-driving period is longer than an hour, the crew may be used as a cover crew, completing at least an extra trip and getting back to the same terminus without interfering with the driving periods that it had previously been assigned. Hence, non-driving periods which are over an hour will be considered cover periods.

\subsection{Results and discussion}

One of the drawbacks of heuristic search methods is that solution quality highly depends on the search parameter values, and extensive testing is required to find suitable values for the parameters. In the present work, tests lead to the choice of tabu list sizes of 15 CTP duties for shifting moves and 11 CTP duty pairs for shifting and pair-shifting moves. A subneighbourhood size of 25 solutions was chosen. Experimentation regarding the strategies for tabu list management requires algorithm specification and is described in Gomes, Cavique and Themido (2002).

As to the objective function, values for $\alpha$ and $\omega$ had to be chosen and a sensitivity analysis was performed to find suitable values for these parameters. Figure 5 depicts the sensitivity analysis of $\alpha$, the parameter of the trade-off term in the objective function. A number of iterations for each value of $\alpha$ was performed; the chart shows the values of $\bar{C}_{S T}$ and $\overline{\Delta C}_{S T}$ of the best solution found (using a Proportional Profile as the target profile).

The two performance measures evolve in opposite directions with the variation of $\alpha$. The best values for $\bar{C}_{S T}$ and (hence) $\bar{C}$, the average number of driving crews, were obtained for a value of $\alpha$ near 1 , while values of $\alpha$ near 0 gave rise to the highest values of $\overline{\Delta C}_{S T}$ and hence to the lowest values of $\overline{\Delta C}$, the average deviation from the target profile. By using a value of $\alpha$ equal to 0.35 high values of $\bar{C}$ will be obtained while $\overline{\Delta C}$ will remain far from its worst values. A sensitivity analysis was also performed on $\omega$, the coefficient of the penalty term; as a result a value of 0.1 was chosen for this parameter.

Improvement of initial solutions (generated by the maximization of cover time heuristic described in Section 4) was tested with individual shifting moves and with switching and pair-shifting moves. While shifting moves only act on working period limits, switching moves change the duties driving periods by recombining them in duty pairs and so there is greater chance for solution improvement; solutions obtained by switching moves were in 




Fig. 5 Sensitivity analysis of parameter $\alpha$ in the objective function

fact superior to the ones generated by shifting moves. By alternating sequences of shifting moves of individual duties with sequences of switching and pair-shifting moves the highest quality solutions were obtained. A description of these experiments is provided in Gomes, Cavique and Themido (2002).

The results presented consist of three CTP solutions for the timetable studied. M90 is the "manual solution" obtained by human planners at Lisbon Underground which displays 90 duties; performance measures were calculated for this solution so that others can be compared with it. Cavique, Rego, and Themido (1999) solved CSP for this timetable obtaining 82 duties; CTP was subsequently solved and the resulting "automatic solution" named A82. Finally, A90 is the solution obtained by solving CTP automatically for the CSP manual solution corresponding to M90. The algorithms were coded in $C$ and ran on an Intel Pentium III 933 MHz PC. Computation times to obtain (improved) solutions A82 and A90 were 10 and 20 minutes respectively (the longest time for the second solution is due to a higher number of feasible CTP duties generated in the search process).

Table 1 characterizes the solutions in terms of duties, namely the number of duties and the average driving time, non-driving time and cover time per duty type. Also shown is the number of two-driving-period duties with cover time (all single-driving-period duties display cover time, so this is not a distinctive measure for these duties). Since duty length is fixed at LU, average driving and non-driving time add up to 8 hours. Average cover time per duty type is computed by adding all cover periods in single or two-driving-period duties and dividing by the duty total; two-driving-period duties without cover time are accounted for as zero terms in the average computation.

Solution composition at the duty level is quite different in the automatic and manual solutions for CSP: the percentage of single-driving-period duties is roughly the double in solution A82 compared to solutions M90 and A90. The latter display the same number of each kind of duty because the moves in the local search procedure do not change the number of duties of each kind. A82 performs the worst in average cover time per duty and percentage of 


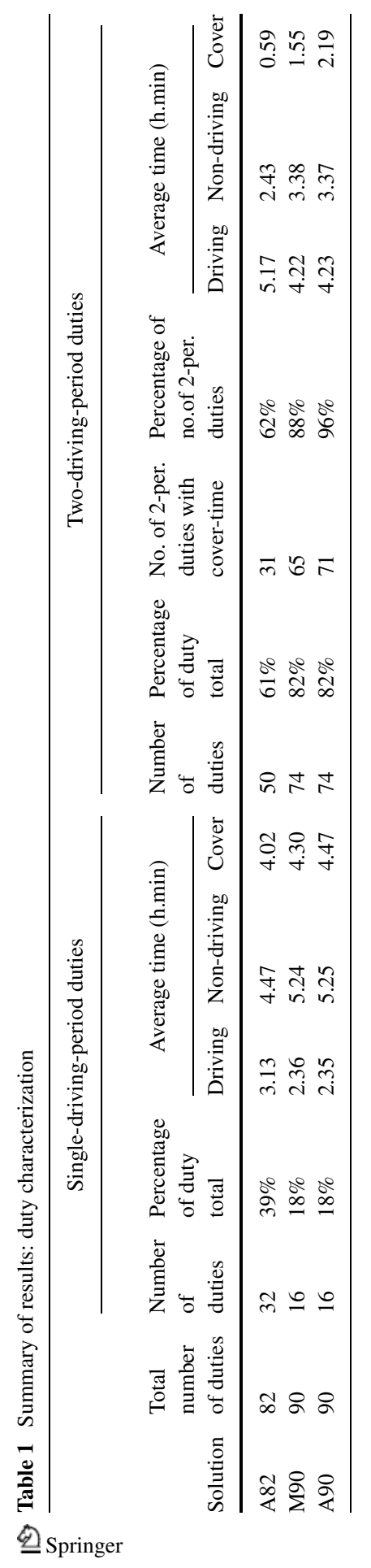


Table 2 Summary of results: cover crew profile performance measures

\begin{tabular}{lllllllll}
\hline \multirow{2}{*}{ Solution } & $\begin{array}{l}\text { Objective } \\
\text { function value }\end{array}$ & Terminus & $\bar{C}$ & $\overline{\Delta C}_{P}$ & $T(Y)(\mathrm{min})$ & $\bar{C}_{\mathrm{I}}$ & $\bar{C}_{\mathrm{II}}$ & $\overline{\mathrm{C}}_{\mathrm{III}}$ \\
\hline \multirow{3}{*}{ A82 } & \multirow{2}{*}{0.966} & Global & 9.0 & 3.6 & 0 & 7.8 & 12.5 & 4.7 \\
& & A & 5.6 & 2.4 & 0 & 5.2 & 7.7 & 2.8 \\
& & B & 3.4 & 1.5 & 0 & 2.7 & 4.8 & 1.9 \\
M90 & \multirow{2}{*}{2.502} & Global & 10.3 & 4.5 & 105 & 6.3 & 11.8 & 9.6 \\
& & A & 6.8 & 3.0 & 0 & 3.9 & 7.3 & 6.8 \\
& \multirow{2}{*}{ A90 } & B & 3.6 & 1.9 & 105 & 2.4 & 4.5 & 2.8 \\
& \multirow{2}{*}{1.026} & Global & 12.5 & 4.5 & 0 & 10.8 & 16.4 & 7.0 \\
& & A & 8.0 & 2.8 & 0 & 7.2 & 10.5 & 4.4 \\
& & B & 4.4 & 1.9 & 0 & 3.6 & 5.9 & 2.6 \\
\hline
\end{tabular}

two-driving-period duties with cover time, a result expected since it uses less duties to cover the same timetable and the average driving time per duty is the highest. Although switching moves exchange driving periods between duties, the average driving time per duty type (single or two-driving-period) is practically the same in solutions M90 and A90. However, solution A90 performs better than solution M90 in the cover time statistics, indicating a more efficient use of the same number of crews.

Table 2 shows the values of the Objective Function and performance measures of the cover crew profile. To provide a better picture of cover crew distribution along the day, the time span of train circulation was split into smaller intervals and the corresponding average number of cover crews also computed. Hence we have in Table 2 (refer to the driving crew profile in Figure 1):

$\bar{C}$ : average number of cover crews in the time span of train circulation (6:30 to 1:40 a.m.)

$\bar{C}_{\mathrm{I}}$ : average number of cover crews at the rush hours (7:15 to $9: 40$ and $17: 15$ to $\left.20: 00\right)$

$\bar{C}_{\text {II }}$ : average number of cover crews between the rush hour periods

$\bar{C}_{\text {III }}$ : average number of cover crews before the first and after the second rush hour periods (during the train circulation period).

A Proportional Profile was used as the target profile. Use of $\overline{\mathrm{C}}_{\mathrm{I}}$ instead of $\overline{\mathrm{C}}$ in the objective function lead to solutions with a better balance between the values of $\overline{\mathrm{C}}_{\mathrm{I}}$ and $\overline{\mathrm{C}}_{\mathrm{II}}$. Also $\overline{\mathrm{C}}_{\mathrm{I}}$ was expressed as a weighted sum of the values at the two terminuses in the objective function, with a higher weight assigned to the performance measure at terminus $\mathrm{B}$; this brought the average number of cover crews at terminus B closer to the one at terminus A.

In conformity with the conclusions drawn from Table 1, the average number of cover crews in the time span of train circulation is the lowest in solution A82 and the highest in solution A90. A better usage of the same number of crews in solution A90 compared to solution M90 results in an increase of two cover crews during train circulation, on average. Besides, cover periods concentrate more in the rush hours and the period between them in solution A90, whilst before the morning rush hour and at night there are less cover crews than in solution M90. This effect is especially remarkable in terminus A. Also solution A90 has no uncovered time intervals while solution M90 has more than $1 \frac{1}{2}$ uncovered hours at terminus B. However, the value of $\overline{\mathrm{C}}_{\mathrm{II}}$ in solution A90 is quite higher than that of $\overline{\mathrm{C}}_{\mathrm{I}}$ which accounts for a deviation from the Proportional Profile similar to the one presented by solution M90.

Solution A82 displays the lowest average number of cover crews but is the solution that deviates less from a Proportional Profile. Even though the value of $\overline{\mathrm{C}}$ is lower than that of 

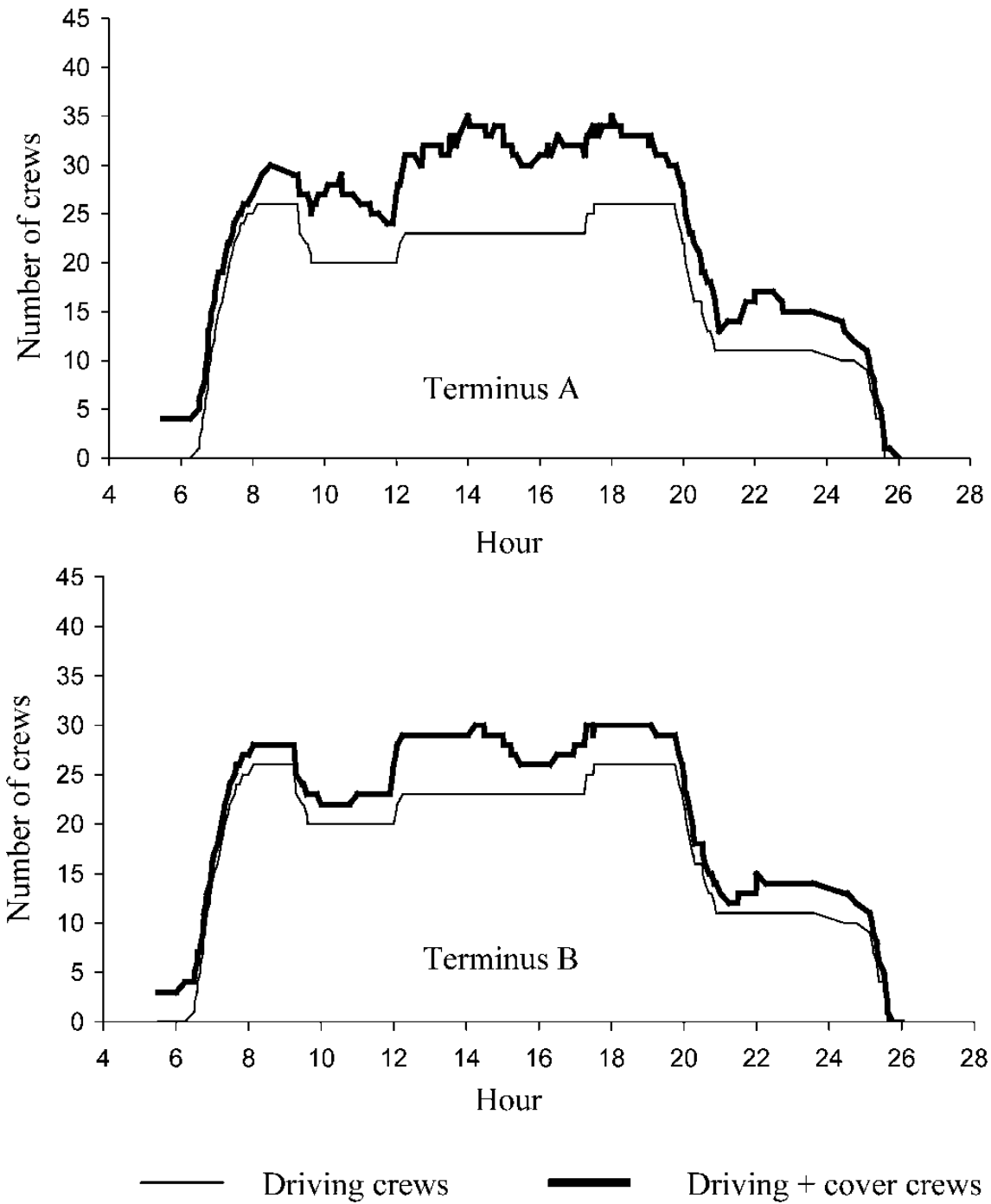

Driving + cover crews

Fig. 6 Cover crew profile for the weekday timetable (solution A82)

solution M90, this solution presents more favourable values of $\overline{\mathrm{C}}_{\mathrm{I}}$ and $\overline{\mathrm{C}}_{\mathrm{II}}$, indicating the superiority of the automatic procedure compared to the manual one.

Figure 6 shows the cover crew profile corresponding to solution A82; the difference between this profile and the target profile in Figure 1 denotes that the problem is highly constrained. Table 3 displays an extract of the duty sheet corresponding to the same solution. All details that the crews need to know are shown; non-driving periods are highlighted and differentiated as cover periods or wasted periods.

Finally Figure 7 depicts the average number of crews versus the number of duties in the three solutions, illustrating the conflicting objectives of minimizing the number of crews needed to cover a vehicle timetable and maximizing the average number of cover crews that result from the duties defined. Solution A90 is more efficient than solution M90 regarding 且 Springer 
Table 3 Extract of a duty sheet (solution A82)

\begin{tabular}{|c|c|c|c|c|c|c|c|c|c|c|c|c|c|c|c|c|c|c|c|c|c|c|c|}
\hline pug Âng & ?̊ & $\frac{n}{2}$ & $\begin{array}{l}8 \\
0 \\
0\end{array}$ & ก̊ & $\begin{array}{l}8 \\
\text { I }\end{array}$ & ֻُ & $\begin{array}{l}8 \\
\infty \\
\infty \\
-\infty\end{array}$ & $\begin{array}{l}\stackrel{0}{1} \\
\infty \\
\infty\end{array}$ & \begin{tabular}{l}
8 \\
\hdashline \\
2 \\
-
\end{tabular} & $\frac{n}{2}$ & $\stackrel{n}{\stackrel{2}{2}}$ & 足 & $\frac{8}{2}$ & ते & $\frac{\text { ก }}{2}$ & ปั่ & 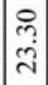 & $\stackrel{n}{?}$ & $\stackrel{?}{\stackrel{f}{-}}$ & $\begin{array}{l}8 \\
\text { ì } \\
\end{array}$ & $\begin{array}{c}8 \\
0 \\
\text { i. }\end{array}$ & $\begin{array}{c}8 \\
8 \\
\text { ¿i }\end{array}$ & \\
\hline $\begin{array}{c}\text { po!̣.. d } \\
\text { ôu!̣!.p-uo } \mathrm{N}\end{array}$ & 4 & & & & & & & 0 & & & 4 & & & 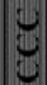 & t) & & & & & & & & \\
\hline snụแ.ı $\mathbf{L}$ & $<$ & $<$ & $\infty$ & $<$ & & $<$ & $<$ & $\infty$ & $<$ & & $<$ & $<$ & & $\infty$ & $\infty$ & $<$ & $<$ & $<$ & & $<$ & $<$ & $<$ & \\
\hline 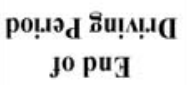 & خิ & בั & $\begin{array}{l}\infty \\
\cdots \\
n\end{array}$ & @ே & & $\stackrel{\circ}{\check{c}}$ & 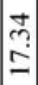 & $\frac{0}{2}$ & ஸ̃ & & $\underline{\infty}$ & શุ̀ & & サ্் & กั่ & तั่ & ป̂ & กุ & & 雍 & mே & $\underline{\underline{Z}}$ & \\
\hline .raqunu u!̣.ı L & 눈 & $=$ & $\ddot{v}$ & $N$ & tith & I & $=$ & $\bar{\lambda}$ & $a$ & 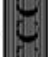 & 2 & ป & 4 & 0 & $\cong$ & $\stackrel{2}{2}$ & $m$ & ป & (c). & $m$ & - & 2 & \\
\hline 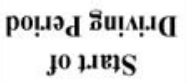 & in & ปู & $\stackrel{2}{\stackrel{2}{ \pm}}$ & ָָ & & בิ & \begin{tabular}{l}
$n$ \\
ปn \\
\hdashline
\end{tabular} & $\begin{array}{l}\tilde{0} \\
\underline{2}\end{array}$ & $\begin{array}{l}\infty \\
\dddot{\sim} \\
\pm \\
-\end{array}$ & & 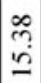 & $\begin{array}{c}\text { 운 } \\
\text { in }\end{array}$ & & $\begin{array}{l}\infty \\
\mathfrak{n} \\
\\
\end{array}$ & $\frac{\infty}{2}$ & o & กิ & $\frac{n}{i}$ & & $\begin{array}{l}\text { ปे } \\
\stackrel{\sim}{*}\end{array}$ & วั่ & ন̀ & \\
\hline snụแ..э. I & $<$ & $<$ & $<$ & $<$ & & $<$ & $<$ & $\infty$ & $<$ & & $\infty$ & $\infty$ & & $<$ & $<$ & $<$ & $<$ & $\infty$ & & $<$ & $<$ & $<$ & \\
\hline $\begin{array}{c}\text { po!̣әd } \\
\text { ธ็แ!ฺ!.p-uo N }\end{array}$ & & & $\mathcal{E}$ & & & & & & & & & & & $\begin{array}{l}0 \\
y\end{array}$ & & & & & & & (4): & & \\
\hline pug увә.. g & $\stackrel{?}{=}$ & $\begin{array}{l}8 \\
\text { i } \\
\text { - }\end{array}$ & 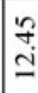 & i̊ & $\stackrel{8}{\text { O }}$ & $\underset{\dot{I}}{\stackrel{8}{0}}$ & ○ & 足 & $\frac{n}{ \pm}$ & $\frac{n}{n}$ & $\begin{array}{l}\because \\
\stackrel{\vartheta}{-}\end{array}$ & $\begin{array}{l}8 \\
0 \\
1\end{array}$ & 尔 & 告 & 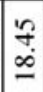 & ? & $\begin{array}{l}\stackrel{0}{0} \\
0 \\
0 \\
\end{array}$ & $\frac{?}{2}$ & $\frac{n}{2}$ & 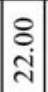 & $\frac{n}{r}$ & $\frac{8}{\grave{2}}$ & \\
\hline 1.1615 yยว.І9 & ? & $\stackrel{8}{0}$ & 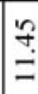 & 总 & $\begin{array}{l}8 \\
\ddot{0}\end{array}$ & @ & $\begin{array}{l}0 \\
m \\
\check{m} \\
-\end{array}$ & $\begin{array}{l}\stackrel{0}{2} \\
\dot{m} \\
-\end{array}$ & $\frac{n}{2}$ & $\begin{array}{l}n \\
\pm \\
\pm\end{array}$ & $\begin{array}{l}\because \\
\ddot{z}\end{array}$ & 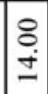 & $\begin{array}{l}\stackrel{n}{f} \\
\because\end{array}$ & 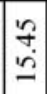 & 年 & ก̃ & $\begin{array}{l}8 \\
0 \\
0 \\
-\end{array}$ & ঙั. & 告 & $\frac{8}{2}$ & 告 & $\begin{array}{l}0 \\
0 \\
0 \\
0\end{array}$ & 픙 \\
\hline  & 4 & 난 & & & 단 & & & & & & & & & & & & ש & 4 & & $\begin{array}{c}\mathbb{C} \\
\mathbb{C}\end{array}$ & & & 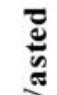 \\
\hline snụய.ıวL & $<$ & $m$ & $<$ & & $<$ & $<$ & $<$ & 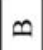 & $<$ & 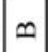 & $<$ & & $<$ & $<$ & $<$ & $<$ & $<$ & $<$ & $m$ & $<$ & $<$ & & \\
\hline 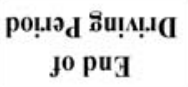 & $\frac{n}{a}$ & $\frac{a}{a}$ & ב & & $\stackrel{+}{n}$ & ָָ & 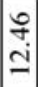 & ָ. & స్ & 곰 & 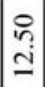 & & ָָ & $\begin{array}{l}n \\
n \\
\pm \\
=\end{array}$ & $\stackrel{\bar{N}}{\underline{N}}$ & in & $\begin{array}{l}\infty \\
\mathfrak{n} \\
\end{array}$ & $\stackrel{n}{2}$ & $\frac{\infty}{\grave{d}}$ & 完 & $\frac{ \pm}{\check{d}}$ & & \\
\hline .raqunu u!b.ıL & 이 & $m$ & $\bar{v}$ & 난 & $\ddot{\imath}$ & $n$ & $=$ & $\nabla$ & $\infty$ & 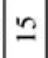 & $\bar{v}$ & $\mathbb{1}$ & $\nabla$ & $n$ & 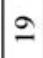 & 으 & $\bullet$ & 으 & 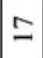 & $\infty$ & \pm & 8 & \\
\hline 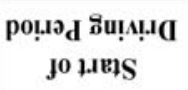 & 움 & ఫே. & ํㅗㄴ & & $\frac{n}{a}$ & ga & $\bar{c}$ & $\stackrel{+}{\mathfrak{m}}$ & กิ & $\begin{array}{l}\infty \\
\tilde{n} \\
0\end{array}$ & $\stackrel{\simeq}{=}$ & & $\underset{\sim}{\beth}$ & ำ & @̋ & $\stackrel{\infty}{ \pm}$ & $\frac{m}{2}$ & in & $\stackrel{g}{g}$ & $\overline{\check{n}}$ & ?ִ & & 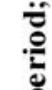 \\
\hline snụu.ıว & $<$ & $<$ & $\varphi$ & & $<$ & $<$ & $<$ & $\infty$ & $<$ & $<$ & $<$ & & $\varphi$ & $\infty$ & $\infty$ & $<$ & $<$ & $<$ & $<$ & $<$ & $<$ & & \\
\hline  & 4 & & & & $\sqrt{4}$ & & & 0 & & & & & & & & & & 4 & & & & & \\
\hline  & 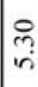 & $\frac{n}{6}$ & $\underset{\sim}{\stackrel{0}{\circ}}$ & ? & $\underset{\infty}{\stackrel{\infty}{0}}$ & $\underset{\infty}{\stackrel{n}{*}}$ & ○ & o & $\stackrel{\circ}{\circ}$ & $\frac{n}{0}$ & $\begin{array}{l}\wp \\
\stackrel{0}{0}\end{array}$ & $\stackrel{8}{\varnothing}$ & $\begin{array}{l}\stackrel{8}{0} \\
\text { i }\end{array}$ & 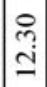 & $\frac{n}{2}$ & $\begin{array}{l}\cong \\
\stackrel{\sim}{9}\end{array}$ & $\begin{array}{l}\stackrel{0}{n} \\
\stackrel{n}{ \pm}\end{array}$ & $\begin{array}{l}\stackrel{n}{2} \\
\stackrel{2}{2}\end{array}$ & $\begin{array}{l}\because \\
0 \\
0\end{array}$ & $\begin{array}{l}8 \\
0 \\
\end{array}$ & $\begin{array}{l}8 \\
\\
-\end{array}$ & $\begin{array}{l}8 \\
\Xi \\
\end{array}$ & 近 \\
\hline 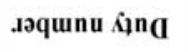 & - & $\cong$ & ป & $\stackrel{\infty}{\sim}$ & 요 & N & $m$ & m & 암 & $\mathcal{F}$ & 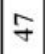 & $\stackrel{\infty}{+}$ & in & $i n$ & in & in & 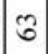 & : & $\Re$ & $\stackrel{\infty}{r}$ & $\infty$ & $\infty$ & \\
\hline
\end{tabular}




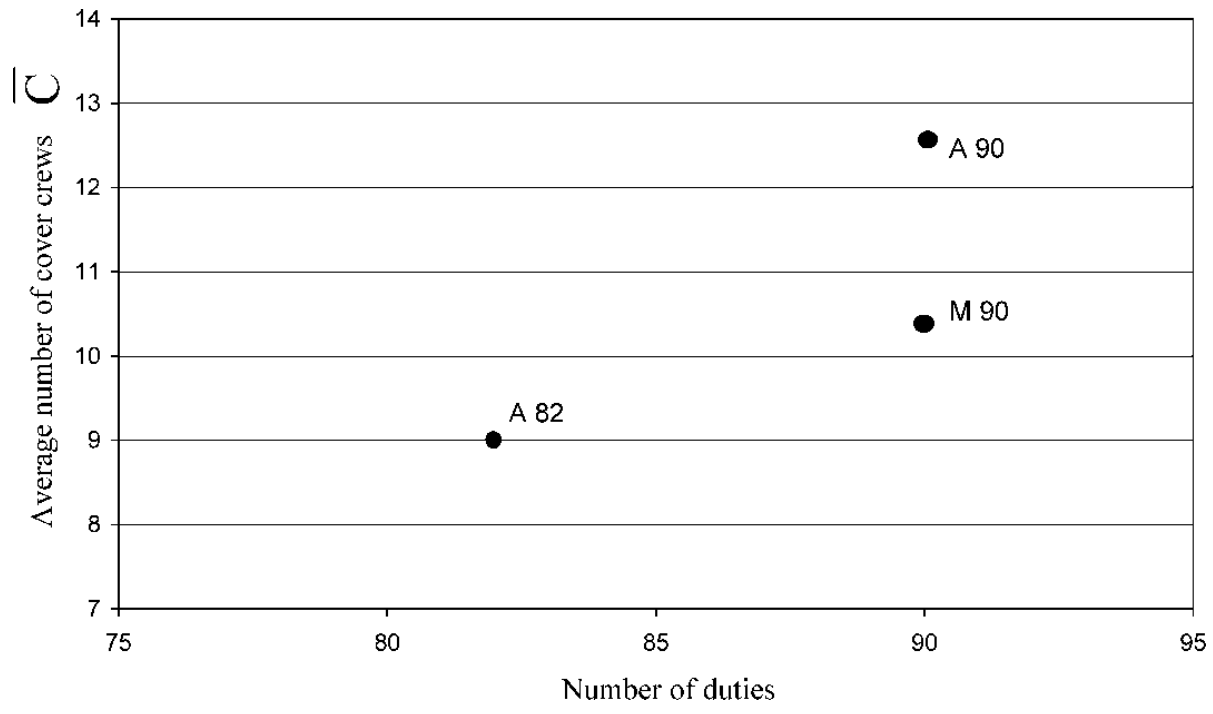

Fig. 7 Comparison of solutions for the weekday timetable

cover crews but is non-comparable to solution A82 because the more favourable $\overline{\mathrm{C}}$ value it displays corresponds to an increase in the number of crews.

\section{Conclusions}

In this paper we define the Crew Timetabling Problem (CTP), a problem faced when constructing duties in transportation companies. The traditional Crew Scheduling Problem (CSP) assigns driving periods to crew duties but does not define the times of duty start and finish as well as break placement. This assignment is made by CTP, the final result being the duty sheet where duties are thoroughly described for the crews. CTP is a resource levelling problem closely related to the one found in the Project Scheduling field; resources to be levelled are the crews in their non-driving periods, which can be used as cover crews. Solving CTP is important in urban transportation companies where driving periods are relatively short compared with the total duty time. We are not aware of any previous description of this problem in the crew scheduling literature.

We propose several performance measures and an objective function for the Crew Timetabling Problem. A heuristic, tabu search-based algorithm is developed to solve the problem which takes as input the CSP solution. A Lisbon Underground weekday timetable is used to illustrate the problem; automatic solutions obtained in reasonable computation time compare favourably with the one constructed by human planners.

We believe that the problem of cover crew levelling is not unique to the company studied, which fully justifies formulating and solving the Crew Timetabling Problem.

\section{Appendix}

A general description of crew duties at Lisbon Underground was provided in section 5-Case study. Further contractual and operational rules that duties have to satisfy can be organized under the following headings: 


\section{Terminuses}

1. Duties must start and finish at the same terminus.

2. The terminuses before and after the break may not be the same. If they are different, time for the travel between terminuses must be provided for in the working periods.

Driving periods

3. For safety reasons, the maximum length of a driving period is $3 \frac{1}{2} \mathrm{~h}$.

4. It is desirable for driving periods to be longer than $1 \frac{1}{2} \mathrm{~h}$ each.

5. It is desirable for the total driving time in a duty to be above $2 \frac{1}{2} \mathrm{~h}$.

\section{Working periods}

6. Working periods have a minimum length of $3 \mathrm{~h}$ and a maximum length of $5 \mathrm{~h}$.

7. The sum of the two working periods in a duty equals $8 \mathrm{~h}$.

8. Duties cannot start before 5:30 or finish after 2:00.

9. Working periods must start and finish at the hour or 15,30 or 45 min past the hour.

10. A minimum time period of 20 min between the start or end of a working period and the start or end of a driving period is required.

\section{Breaks}

11. All duties have a break lasting $1 \mathrm{~h}$.

12. The break must happen during the functioning of the canteen (11:00-15:00 and 17:0022:00) except for duties finishing between 14:00 and 14:30 or 21:00 and 21:30.

Acknowledgments The authors gratefully acknowledge the careful review by two anonymous referees whose comments helped to improve this paper. They also thank César Rego for providing a reference that was important to write the paper.

\section{References}

Bandelloni, M., M. Tucci, and R. Rinaldi. (1994). “Optimal Resource Levelling Using Non-Serial Dynamic Programming." European Journal of Operational Research 78, 162-177.

Bodin, L. and D. Berman (eds.). (1975). "Workshop on Automated Techniques for Scheduling of Vehicles Operator for Urban Transportation Services.” Pre-print.

Cavique, L., C. Rego, and I. Themido. (1999). "Subgraph Ejection Chains and Tabu Search for the Crew Scheduling Problem.” Journal of the Operational Research Society 50, 608-616.

Daduna, J. and A. Wren (eds.) (1988). Proceedings of the Fourth International Workshop on Computer-Aided Scheduling of Public Transport. Lecture Notes in Economics and Mathematical Systems, Springer-Verlag.

Daduna, J., I. Branco, and J. Paixão (eds.) (1995). Proceedings of the Sixth International Workshop on Computer-Aided Scheduling of Public Transport. Lecture Notes in Economics and Mathematical Systems, Springer-Verlag.

Desrochers, M. and J.-M. Rousseau (eds.) (1992). Proceedings of the Fifth International Workshop on Computer-Aided Scheduling of Public Transport. Lecture Notes in Economics and Mathematical Systems, Springer-Verlag.

Glover, F. (1995). “Tabu Search Fundamentals and Uses.” Technical Report, Graduate School of Business and Administration, University of Colorado at Boulder.

Glover, F. and M. Laguna. (1997). Tabu Search. Kluwer Academic Publishers. 
Gomes, M.C., L. Cavique, and I. Themido. (2002). "An Algorithmic Approach for the Crew Timetabling Problem.” Technical Report, CESUR_-Instituto Superior Técnico.

Hartley, T. (1981). "A Glossary of Terms in Bus and Crew Scheduling." In: Computer Scheduling of Public Transport. Urban Passenger Vehicle and Crew Scheduling, A. Wren (ed.), North-Holland, pp. 353-359.

Neumann, K. and J. Zimmermann. (1999). "Resource Levelling for Projects with Schedule-Dependent Time Windows." European Journal of Operational Research 117, 591-605.

Rousseau, J.-M. (ed.). (1985). Computer Scheduling of Public Transport 2. North-Holland.

Wilson, N. (ed.) (1999). Proceedings of the Seventh International Workshop on Computer-Aided Scheduling of Public Transport. Lecture Notes in Economics and Mathematical Systems, Springer-Verlag.

Wilson, R.J. and J.J. Watkins. (1990). Graphs—An Introductory Approach. John Wiley \& Sons.

Wren, A. (ed.) (1981). Computer Scheduling of Public Transport. Urban Passenger Vehicle and Crew Scheduling. North-Holland. 